\title{
VALIDACIÓN DE UN MATERIAL EDUCATIVO ORIENTADO A PROMOVER LA HIGIENE ORAL DIRIGIDO A ESCOLARES ENTRE 5 Y 7 AÑOS DE EDAD*
}

\author{
${ }^{1}$ Monica Tatiana Prieto M., ${ }^{1}$ Diana Carolina Otero Q., ${ }^{2}$ Sonia Esperanza Sierra, ${ }^{2}$ Sergio Camargo, ${ }^{3}$ Sonia Constanza Concha S. \\ ${ }^{1}$ Estudiante VII semestre, F de Odontología, U. Santo Tomas, ${ }^{2}$ Odontólogo U. Santo Tomás \\ ${ }^{3}$ Odontóloga, U. Santo Tomás, Especialista en Educación y Comunicación para la Salud, \\ Magíster en Epidemiología, U. Industrial de Santander, Docente U. Santo Tomás.
}

Autor responsable de correspondência: Mónica Tatiana Prieto M.

Dirección de correo electrónico: mony267@hotmail.com

Tercer Puesto en el Concurso Colgate para Proyectos de Investigación/Intervención Comunitaria (2006)

\section{RESUMEN}

Objetivo: Validar un material educativo orientado a promover la higiene oral en escolares entre los 5 y 7 años de edad. Materiales y Métodos: Se realizó un estudio cualitativo con base en la teoría fundada y soportado en la recolección de la información mediante la técnica de grupos focales, que incluyó el trabajo con 5 grupos integrado cada uno por 6 niños entre los 5 y 7 años de edad vinculados a instituciones públicas de Bucaramanga. Previa a la recolección de los datos se hizo un abordaje teórico inicial, se procedió a la recolección. La información se recopiló en archivos de audio, se transcribió, codificó, categorizó, analizó e interpretó.

Resultados: Se establecieron relaciones teóricas y se hicieron sugerencias orientadas a mejorar el material educativo. Se logró concluir que el material educativo evaluado debe replantear aspectos relacionados con los mensajes que los niños perciben sobre la dependencia que tienen del odontólogo y fomentar la autoeficacia hacia su higiene oral. Se debe reducir o controlar las escenas violentas.

Conclusiones: Debe procurarse que el mensaje básico de cuidado sea claramente percibido por los receptores del elemento educativo. [Prieto MT, Otero DC, Sierra SE, Camargo S. Concha SC. Validación de un material educativo orientado a promover la higiene oral dirigida a escolares entre 5 y 7 años de edad. Revista Ustasalud Odontología 2007; 6: 37 - 44]

Palabras clave: Material educativo, Higiene oral, Escolares.

\section{VALIDATION AN EDUCATIVE MATERIALS THAT PROMOTE THE ORAL HYGIENIC IN FIVE TO SEVEN YEARS OLD SCHOLAR}

\begin{abstract}
Objective: The aim of this work was to validate educative materials that promote the oral hygienic in five to seven years old scholar. Material and Methods: A qualitative investigation with base in the founded theory was made and five focus groups integrate by six children between six to seven years old were done. Previous to collected data, an initial theoretical boarding became was come to the harvesting. The information was compiled in audio archives, transcribed, codified, categories, analyzed and interpreted.

Results: From the obtained results, theoretical relations settled down and oriented suggestions were made improve the educative material. It was managed to conclude that the evaluated educative material must reframe aspects related to the messages that the children perceive on the dependency which they have of the dentist and to foment selfcare towards their oral hygiene. One is due to reduce or to control the violent scenes.

Conclusions: It must be procured that the basic message be clearly perceived by the receivers of the educative element.
\end{abstract}

Key words: Educative material, Oral hygiene, Scholar.

Recibido para publicación: 23 de mayo de 2007. Aceptado para publicación: 30 de julio de 2007.

\footnotetext{
* Grupo Semillero de Investigación.
} 


\section{INTRODUCCIÓN}

A partir de la creación de la Ley 100, la prevención se hace indispensable dentro de los programas de salud, ya que su filosofia se enfoca a alcanzar la meta de mantener la población sana con la menor cantidad de consultas asistenciales para el siglo XXI. ${ }^{1-4}$

La odontología ha desarrollado a través del tiempo, el conocimiento necesario para identificar los principales factores de riesgo y la manera de prevenirlos. La promoción de la salud bucal y la prevención de los problemas se sitúan así en el control de los determinantes de la salud, mediante mejores condiciones de vida en las poblaciones, el control de factores de riesgos específicos y el desarrollo de habilidades personales. ${ }^{5}$

La prevención de los problemas de salud bucal se debe hacer para toda la población pero por supuesto, orientar sus mayores esfuerzos a grupos prioritarios de riesgo como niños y adolescentes, ancianos, discapacitados, mujeres gestantes, poblaciones marginales. ${ }^{6}$ Además, estos programas deben ser activos y eficientes y desarrollarse con la mayor sencillez posible para que estén en capacidad no solamente de prevenir la enfermedad sino de promover condiciones de vida saludables. ${ }^{4}$

Parte importante de la prevención en odontología es la educación para la salud, la cual se define como "las oportunidades de aprendizaje creadas y conscientemente proyectadas para facilitar cambios de conducta encaminados a una meta predeterminada". ${ }^{7}$ Se espera que la educación para la salud se convierta en un potente instrumento de cambio colectivo de las condiciones que determinan la salud, pero que además predisponga a los individuos a comportamientos voluntarios que refuercen su estado de salud.

Para que sea exitosa la educación para la salud debe tener en cuenta el entorno, las necesidades del sujeto y su estilo de vida, las habilidades personales, estas últimas de gran importancia en las actividades involucradas con el cuidado bucal. ${ }^{8}$ Por lo tanto, en la medida que el comportamiento personal y los estilos de vida están involucrados con una mayor probabilidad de tener problemas de salud, la prevención debe contemplar dentro de sus principales componentes la educación en salud, como medio susceptible para modificar los comportamientos de riesgo. ${ }^{9}$

La premisa que ha orientado los programas educativos en el campo de la salud odontológica, se sustenta en la creencia de que la estimulación a través de charlas, películas, demostraciones, y demás, establecen las condiciones necesarias para el desarrollo de patrones de conducta que permitan el alcance de niveles de salud óptimos. ${ }^{10}$
Una revisión de la literatura existente, permite identificar trabajos científicos orientados a evaluar la efectividad de los programas preventivos en odontología, en sus diferentes modalidades. ${ }^{11-14}$

Es del consenso general, que la motivación y el reforzamiento de la conducta se constituyen elementos claves en el desarrollo de los programas. Así mismo, la literatura existente permite identificar varios factores que inciden en la conducta del niño y su respuesta a las estrategias de motivación. No obstante, la mayoría de las veces, los patrones de comportamiento son atribuidas a las características innatas del niño, al estadio de su desarrollo y al rol de sus padres. ${ }^{15}$ De ahí la importancia de implementar mecanismos que puedan evaluar el material educativo que se utiliza con el fin de reforzar conductas básicas de autocuidado oral y determinar cuál es su real impacto en los procesos de enseñanza aprendizaje en educación de salud bucal.

Los programas de prevención deben estar enfocados a la educación en salud oral para que los niños puedan adquirir medidas de higiene oral que sean aceptadas por sí mismos, por lo tanto, deberían intensificarse los esfuerzos por aumentar la difusión de materiales educativos especialmente para niños quienes son los que más pueden beneficiarse de ellos). ${ }^{15}$

Es importante resaltar la ausencia de materiales educativos en salud oral que sean especiales para niños y que a la vez hayan sido validados por ellos mismos. La creación de un material educativo didáctico e ilustrado dirigido a niños en proceso de aprendizaje, que haya sido sometido a evaluación por parte de ellos mismos no sólo brindará seguridad en la recepción del mensaje a transmitir sino también la aceptación por parte del público al cual se dirige el material educativo, lo que garantizará un impacto positivo en el grupo intervenido.

Considerando el marco referencial señalado el objetivo de este trabajo es validar un material educativo orientado a promover la higiene oral en niños entre 5 y 7 años de edad vinculados a instituciones educativas de Bucaramanga

\section{MATERIALES Y MÉTODOS}

Se realizó un estudio cualitativo fundamentado en la teoría fundada y basado en la recolección de la información mediante la técnica de grupos focales. ${ }^{16,17}$ Se realizaron cinco grupos focales conformados cada uno, por seis niños entre los 5 y 7 años de edad. Los grupos focales involucraron niños de diferentes instituciones educativas públicas, del área metropolitana de Bucaramanga. 
El proceso desarrollado fue el siguiente:

- Previa a la recolección de los datos se hizo un abordaje teórico inicial base para el desarrollo del proceso.

- Se procedió a la recolección de la información a partir del interrogatorio en los grupos focales realizados. La información se recopiló en archivos de audio, se transcribió, codificó, categorizó, analizó e interpretó.

- Paralela a la actividad de interrogatorio se elaboró un registro de lo observado en cuanto a actitudes, gestos e impresiones de los participantes que se integró al proceso de codificación análisis e interpretación; actividad realizada por un observador previamente entrenado.

- A partir de los resultados obtenidos, se establecieron relaciones teóricas y se hicieron sugerencias orientadas a mejorar el material educativo.

La presente investigación se acogió a las normas éticas establecidas por la Resolución 008430 del Ministerio de Salud, de la República de Colombia.

\section{Análisis de la información:}

En el proceso investigativo se exploraron las percepciones de los niños y las niñas involucrados en el trabajo sobre dos aspectos fundamentales. El primero relacionado con el contenido y el segundo con la presentación del material

\section{RESULTADOS}

\section{ASPECTOS RELACIONADOS CON EL CONTENIDO}

\section{Percepción inicial:}

En aspectos de contenido, inicialmente, se interrogó a los menores sobre qué otro nombre le daría al material analizado. Se percibieron dos tipos de respuestas las que asociaban al material con "los dientes felices, dientes limpios"," los dientes tienen amigos", "las aventuras de los dientes", "los dientes amigos", "los dientes sanos", "las muelitas sanas" y "aprendiendo a cuidarse los dientes"; "los amigos felices", "los amigos unidos", fueron otras expresiones utilizadas por los niños para referir el material observado.

Por otro lado, dentro de las respuestas también se hizo alusión a: "ia caries invade las muelitas!", "la muelita y su pandilla" y "las muelitas sacar".

Se podrían percibir respuestas asociadas a la higiene dental, aspecto que es positivo, pues está orientado al tema propuesto; también se hace alusión en forma reiterativa a aspectos relacionados con la amis- tad, tópico que es relevante considerado el grupo sobre el cual se trabaja, pero podría convertirse en un elemento distractor que podría impedir captar la idea central. ${ }^{17}$ Por otra parte, las respuestas relacionadas con invasión, pandilla y sacar las muelitas podrían indicar relaciones negativas hacia la salud oral; adicionalmente, es probable que los niños perciban algunas escenas como violentas aunque no es posible descartar la influencia del contexto y de los medios de comunicación y que podrían orientar este tipo de respuestas. ${ }^{18-20}$

\section{Gusto por el material:}

El elemento comunicativo les gustó "porque habla de los dientes y las bacterias, de la caries y de la necesidad de cuidarse"; también reportaron que les gustaba porque "tenían que lavarse los dientes"; les mostraba cómo cepillarse y las partes que se deben cepillar. Refieren además que "si no se cuidan los dientes se vuelven amarillos y la caries los ataca" tal como le pasó al protagonista de la historia. Otros reportaron que "le gustaron los superhéroes porque alguien venía a salvarlos".

Es importante anotar que los reportes iniciales están orientados al cuidado oral; se podría percibir además la influencia social que ha generado el blanqueamiento dental y la creencia de que los dientes deben ser blancos como reflejo de una condición dental normal.

Llama la atención la percepción del superhéroe que los niños manifiestan que, por una lado, pueden reflejar imágenes modelo; pero que, por otra parte, atribuyen a otros (los superhéroes) la posibilidad de mantenerse bucalmente sano; hecho que podría reflejar la percepción de baja auto-eficacia frente a su cuidado bucal y, por otro lado, la imagen "medicalizada" del cuidado que puede proveer el odontólogo.

Otros, manifiestan abiertamente que el material no les gustó, o sólo parcialmente; incluso otro expresa que no sabe si realmente le gustaba. Aunque no explicitan las razones para hacer tales afirmaciones; usualmente este tipo de expresiones fueran más frecuente en los niños y en los de mayor edad.

En términos generales, los grupos reportaron gusto por el material y lo relacionaron con la posibilidad que tenía de enseñarles a cuidarse los dientes y la importancia de esto, para evitar que se les dañen o se vuelvan amarillos.

\section{La historia que les cuenta el material:}

Expresiones como: "Se trata de una muelita que se iba caído y la placa la iba a matar al diente y la punieron en la cama y después se curó". Otros refieran 
una historia "de unos buenos amigos a los que las bacterias querían atacar y que un día que estaba sólo lo atacaron y lo dejaron mal herido, el doctor. Lo quería ayudar, el aceptó que lo ayudaran, se sanó y quiso ir a jugar." Resaltan frases como: "El diente dijo: quién podrá ayudarme y salió un Doctor".

Para otro la historia trata de que "Cokis no quería jugar con sus amigos y entonces llegó McKaries, entonces lo llevaron al hospital y superdiente lo atendió y después nunca más lo volvieron atacar los McKaries". Similar a la anterior, otro niño reportó "Era un diente que los amigos lo invitaban a jugar y él no aceptaba y un día llegó McKaries y la muelita fue atacada y entonces la muelita estuvo gravemente herida entonces los amigos llegaron y lo llevaron al hospital y el doctor luego lo sanó".

Expresiones como las anteriores parecen indicar que la salud oral se alcanza sólo cuando el odontólogo realiza procedimientos operatorios y no se observa la opción que tiene cada persona de aplicar medidas de higiene oral que le permitan mantenerse sano.

Paralelo al tópico relacionado con la condición oral se hizo evidente aspectos relacionados con la amistad y la solidaridad en frases como: "Se trata de un diente que era sólo, que cuando los amigos intentaban jugar y eso no dejaba y un día llegaron las caries y los dientes empezaron a gritar y los demás ayudaron al diente y ya", otra como "Una pandilla de dientes que juntos hacían cosas que si un diente estaba en problema los otros dientes lo ayudaban".

\section{La percepción de la historia referida:}

Los escolares refieren la importancia con expresiones como: "Si porque es de los dientes", "Si no nos cepillamos eso nos puede pasar", "Nos enseña a cuidar los dientes", "Nos enseña a cuidar los dientes, a lavarnos, porque si no la caries nos va a comer nos daña y quedamos muecos como los abuelitos". Todas estas expresiones reflejan el impacto que sobre el cuidado oral puede tener el material educativo y son consecuentes con el objetivo propuesto. Por otro lado, se hace evidente desde edades muy tempranas la relación que se establece de la vejez con la pérdida dental y de las potenciales implicaciones que esto tiene sobre los hábitos de auto-cuidado que para el futuro se podrían adoptar.

También se escucharon respuestas como: "Porque uno debe ser solidario, porque uno no se puede defender a una misma, toca tener amigos para que le ayuden, cokis no aceptaba la invitación y se quedó sólo"; otro, por su parte, afirmó que "es importante compartir y jugar con los amigos, el diente aprendió que no debe ser egoísta". Aspectos que encajan más con la amistad y la solidaridad.
La potencial problemática ante esta doble percepción radica en, hasta qué punto, los niños y las niñas logran integrar las dos temáticas o si la segunda puede llegar a distraer a los lectores frente al cuidado oral, hecho que parece haber ocurrido y que ya fue referido. ${ }^{17}$

\section{La utilidad de la historia:}

"Para que nos cuidemos los dientes, para que no nos invada la caries, cuidarnos las muelitas del grupo armado McKaries", "para los dientes", "Porque si uno no se cepilla los dientes se le vuelven ...porque cuando las caries atacan los dientes después les da dolor de muela y puede perder los dientes". "Porque debemos comprender que uno no debe dejar de lavarse los dientes, uno debe cuidarse los dientes", "uno debe bañarse los dientes todos los días".

Las expresiones anteriores se escucharon con frecuencia, cuando se interrogó a los escolares sobre la utilidad de la historia. Las primeras frases se asocian de alguna manera con el temor y podría hacer llegar a pensar que el material utilizado utilizaría bases fundamentadas en las teorías del comportamiento relacionadas con la protección-motivación; las últimas, por su parte parecen basarse en la teoría de la acción razonada, aspecto que es importante, si se pretende que los niños y las niñas asuman responsablemente su cuidado oral. ${ }^{21}$

\section{¿Los personajes de la historia que llamaron su atención?}

"A mí Cokis porque enseña que uno debe dejarse lavar los dientes", "el doctor. superdiente porque ayuda a cokis a sanarse", "Me gustaron las bacterias porque llevaron a la muelita a la clínica y salió un doctor y de una se sanó" "Tatys y el doctor porque nos ayuda a no descuidar los dientes y nos enseña cómo lavarlos". En las tres primeras frases se hace nuevamente evidente la dependencia que percibe el escolar, frente al mantenimiento de su salud oral. La última expresión parece indicar mayor independencia y es característica de los niños de mayor edad.

\section{¿Qué le faltó a la historia?}

Los niños de mayor edad perciben la historia como "infantil" y lenta. Apreciaciones como "los dibujos son bonitos pero necesitan más acción, son infantiles, para 6 añitos", "faltó acción como guerra,... mentira no", "Faltó más acción como que el grupo armado McKaries tuviera pistolas así paapaapaa..paapa, como el CSI caries, ELN caries".

Además, parecen mostrar la influencia que han tenido sobre ellos programas televisivos con algún contenido de violencia y la misma situación del país que no es ajena a este hecho. ${ }^{18-20}$ 


\section{¿Qué le cambiaría a la historia?}

Los escolares parecen indicar que desean un mayor protagonismo del odontólogo particularmente en acciones tienen que ver con evitar el daño sobre sus dientes con frases como: "Que mostrara cuando el señor esta abriendo la boca y le saca la placa", "que el doctor sacara un cepillo y barriera la caries", "que el doctor superdiente tuviera más dibujos o que fueran escritos"

"Que Cokis no fuera mala, que aceptara la invitación de sus amigos porque al no aceptar sus invitaciones se quedó sólo", "que desde la primera parte todos fueran amigos". También apelan a la importancia de la amistad y la solidaridad, cualidades que deben evidenciarse en las personas en forma permanente

"Yo le cambiaría a McKaries para que fuera más cruel y violento", "cuando el malo estaba diciendo ja.ja. porque quiero que los dientes se enfermen", "cuando iban a atacar". Podría evidenciar las escenas que los niños y las niñas relacionan con la violencia percibida a través de los medios de comunicación o con situaciones de conflicto que han percibido en su entorno..$^{18-20}$

\section{¿Qué no le agradó?}

"Que las bacterias dañaran el diente porque el no estaba haciendo nada malo", "cuando las bacterias atacaron a muelitas", "cuando se estaba muriendo", "que la caries tenía puyas", "no me gustó cuando estaba diciendo que las muelita se sentía triste y se burlaron de ella". Lo anterior enfatiza el rechazo que los niños manifiestan frente a los hechos dolorosos o injustos y del profundo impacto que estos tienen en su vida. Vilches reporta que los niños entre los 3 y los 8 años son muy sensibles a las emociones del miedo. En general los niños de esta edad temen a la oscuridad, la muerte y a los seres sobrenaturales o deformes. Hecho que se hizo evidente en el presente trabajo. ${ }^{22}$

\section{ASPECTOS RELACIONADOS CON LA PRESENTA- CIÓN DEL MATERIAL}

\section{El diseño del material:}

Los niños reportaron las siguientes apreciaciones sobre el material: "Bonito tienen buen color y los dibujos estaban bien hechos", "bonito porque salen muchos colores y muchos dibujos, porque había muchas palabras donde uno podía aprender a leer" Lo cual parece indicar que es un material atractivo, pero cuyos contenidos obligan a que el usuario sea una persona que sepa leer o esté en ese proceso. También parece indicar la necesidad que exista una persona que apoye el uso de este material, cuando se utiliza en niños o niñas que no sepan leer.

\section{Los colores:}

La forma como se presenta el material y en particular el uso adecuado de los colores son aspectos que los niños y las niñas evidentemente aprecian; por otra parte, este factor se verá fuertemente influenciado por la subjetividad. Durante el proceso se evidenciaron expresiones tales como:"Los colores estaban muy vivos, pero el azul sobre todo; con muchos colores menos el negro". "Los colores están combinados, el diente blanco, el cepillo fucsia". "Son bonitos porque son suavecitos"

Es importante recordar que el color es una parte del espectro lumínico, es energía vibratoria y tiene el poder de afectar de diferente forma al ser humano, depende de su longitud de onda, produce diferentes sensaciones de las que normalmente no se es consciente.

Además, de muchas otras funciones que cada material educativo pueda tener, ante todo intenta comunicar. Y lo hace con las palabras, con las imágenes y con los colores. Los publicistas, los diseñadores industriales y los comunicadores son conscientes de esto y utilizan los colores para asociarlos de forma coherente con el tipo de producto y a quien lo quieren hacer llegar. ${ }^{22}$

En el grupo evaluado se hizo énfasis particular en el color azul que se asocia con lealtad, confianza, sabiduría e inteligencia. El negro por su parte se asocia al miedo y a lo desconocido. Aspectos relevantes ya que coinciden con lo reportado por los escolares a lo largo del proceso investigativo.

\section{DISCUSIÓN}

La producción de material educativo orientado a promover el cuidado oral no debe dejar de lado las leyes del mercado, en el que los libros de caricaturas se constituyen en la oferta natural y prácticamente única, pero deben implementarse como una oferta atractiva que despierte el interés de los niños y las niñas. ${ }^{22}$

"El niño que reconoce el texto como fruto de su trabajo, como su creación, siente la alegría del artista frente a su obra" y ese debe constituirse en uno de los elementos básicos que deben estimular la producción y validación del material educativo pues cuando los niños son tomados en cuenta, cuando la corrección es colectiva, cuando se encuentra significado a un texto, entonces se puede decir que se promueve un aprendizaje con sentido. Una de las potenciales razones que hacen que los mensajes de educación en salud oral no sean recibidos por los niños, es que quizás no se han tenido en 
cuenta en la producción de material que a ellos les interese y no se ha llegado con mensajes que realmente les permitan identificarse con su realidad. ${ }^{23}$

El material educativo orientado a promover la salud debe propiciar espacios de bienestar y salud, por lo cual es fundamental el control de las imágenes que pueden tener un potencial efecto negativo en los niños y las niñas.

\section{CONCLUSIONES:}

El material educativo evaluado debe replantear aspectos relacionados con los mensajes que los niños perciben sobre la dependencia que tienen del odontólogo frente a su cuidado oral y fomentar la autoeficacia hacia el su higiene oral.
Así mismo, debe reducir o controlar las escenas que podrían potencialmente impactar en forma negativa en los niños y las niñas y que pueden exponerlos a hechos violentos en forma innecesaria.

Dentro de un material es difícil el manejo exclusivo de una temática, pero en el material orientado a promover hábitos saludables, particularmente los orientados a la salud bucodental, debe procurarse que el mensaje básico de cuidado sea claramente percibido por los receptores del elemento educativo por lo cual es importante que se controle este aspecto en particular en el elemento educativo que fue objeto de la validación.

\section{La historieta de Cokis}
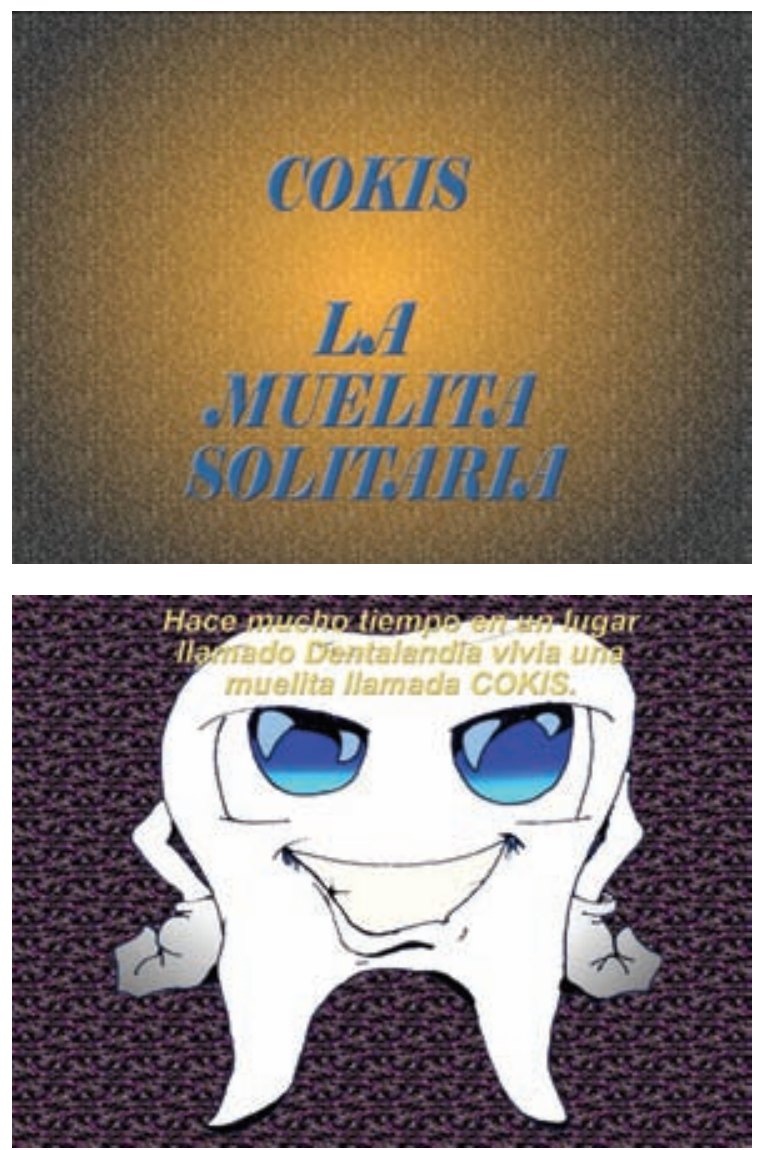
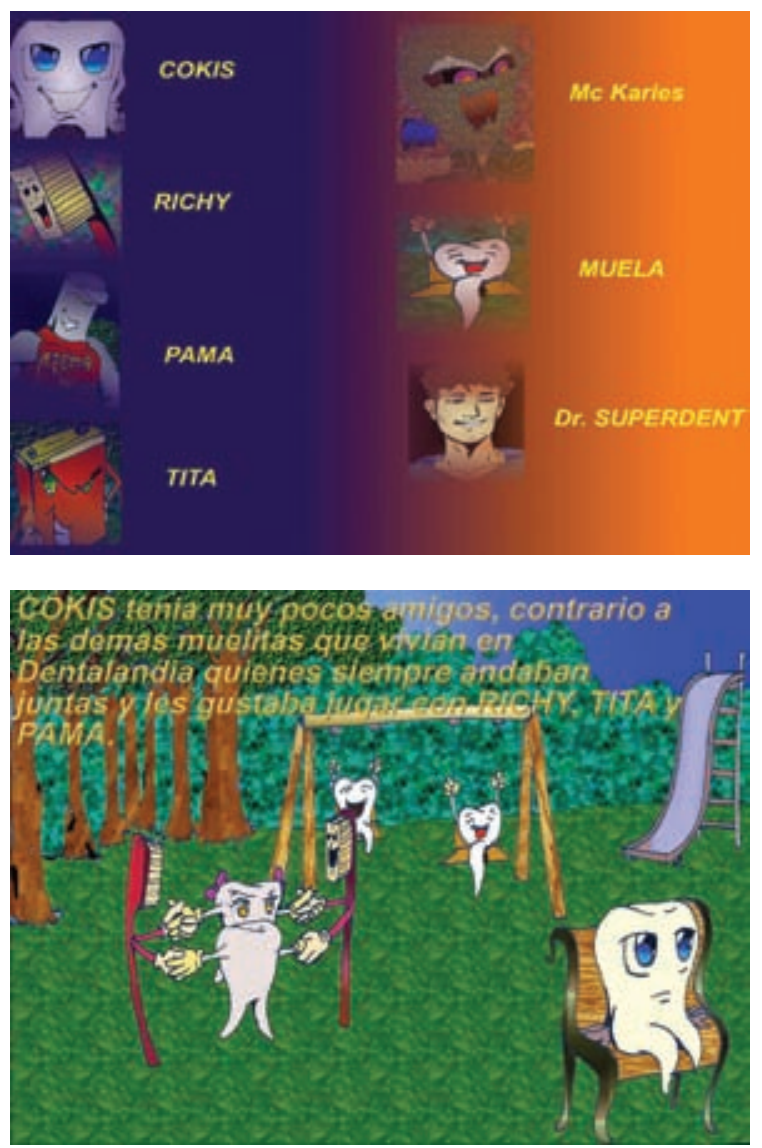

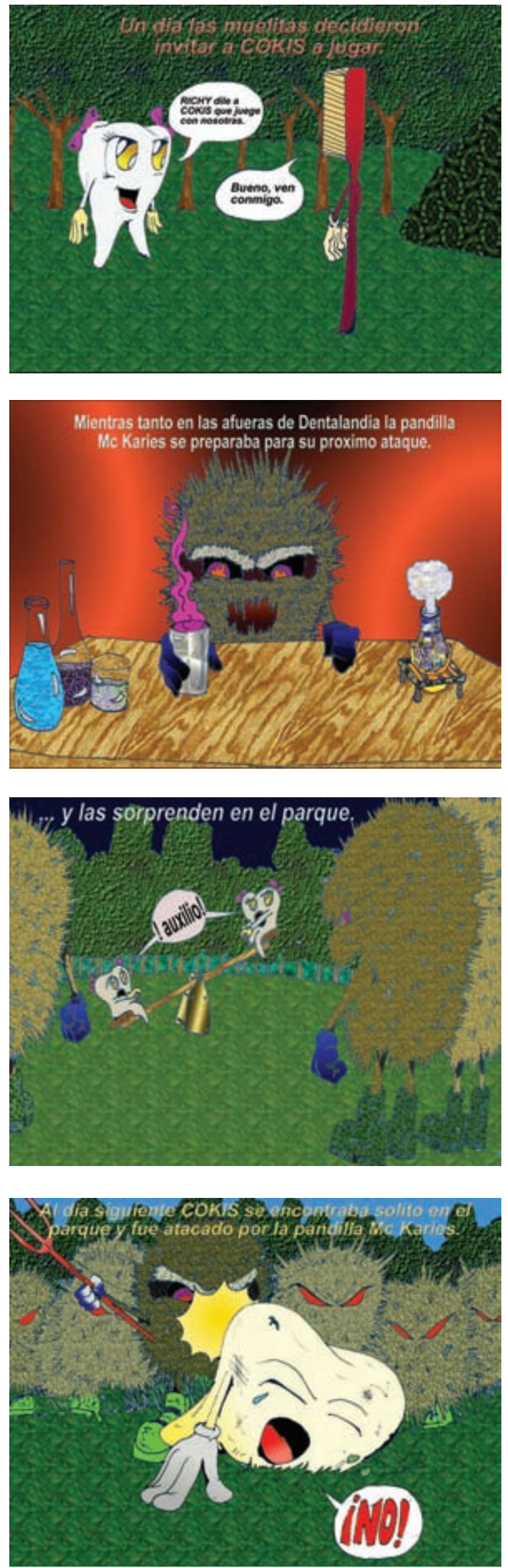
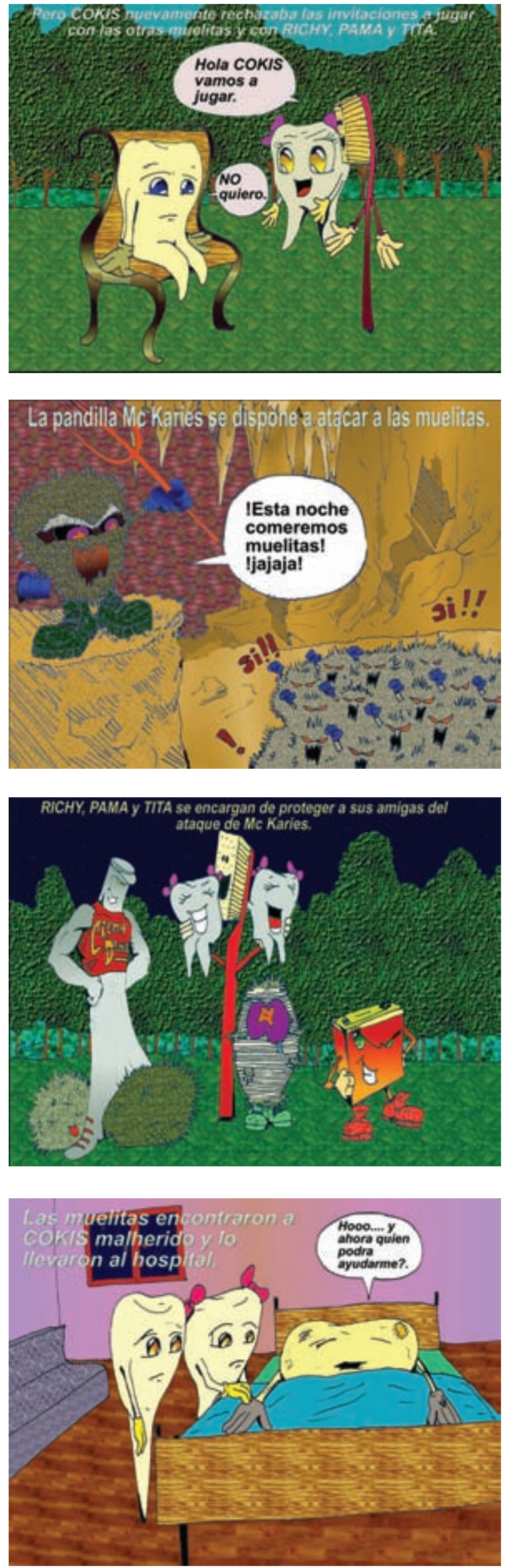

43 

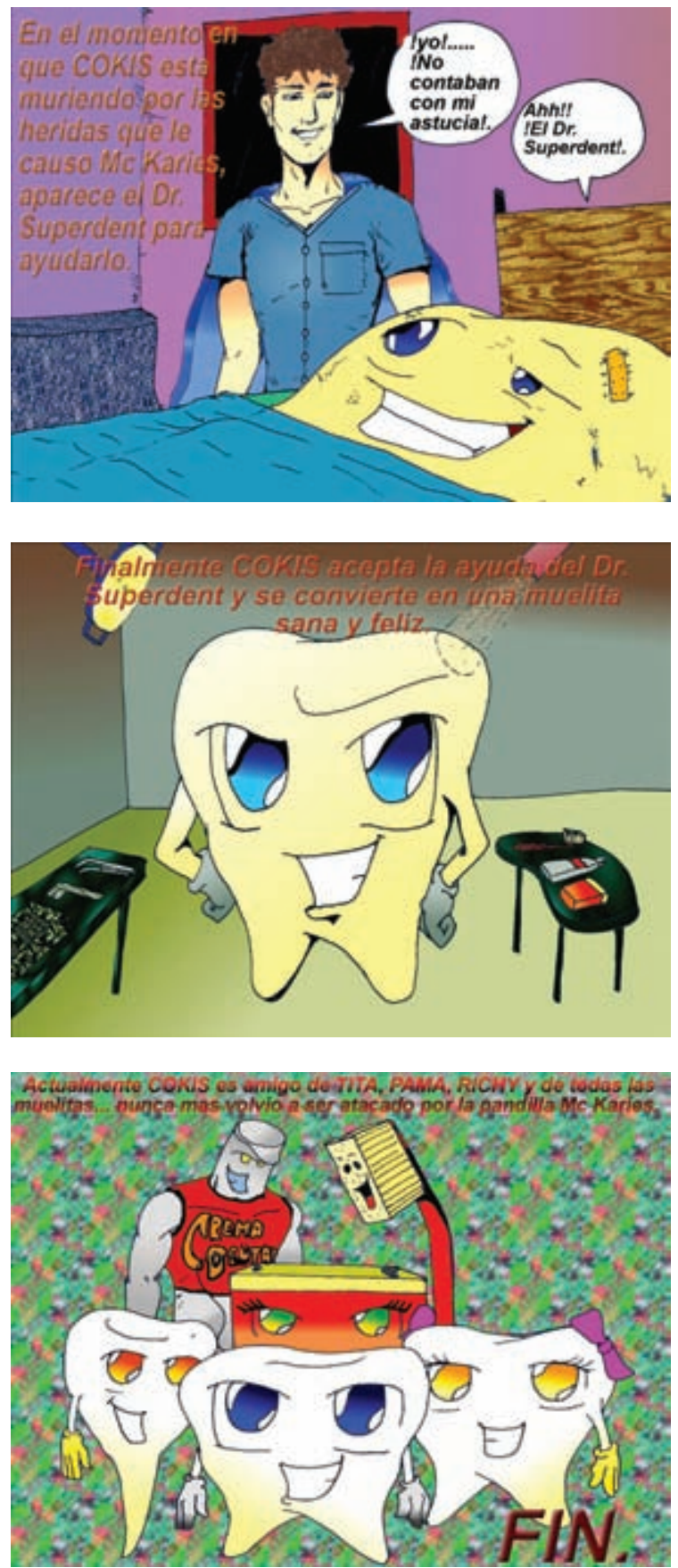

\section{BIBLIOGRAFÍA}

1. Restrepo CC. Impacto del programa de promoción y prevención en salud oral aplicado a escolares. Revista CES Odontología 1999; 12: 42 - 48.

2. Gómez A, Moreno I, Casa JV, Paredes N. La reforma a la seguridad social. Tomo 1. Antecedentes y resultados, Editorial Carrera Séptima Ltda., Santa fe de Bogota, 1994. pp. 1 - 273

3. Gómez A, Moreno I, Casa JV, Paredes N. La reforma a la seguridad social. Tomo II. Decretos reglamentarios, Editorial Carrera Séptima Ltda., Santa fe de Bogota, 1994. pp. 55-85.

4. Gómez A, Moreno I, Casa JV, Paredes N. La reforma a la seguridad social. Tomo III. Anexo documental, Editorial Carrera Séptima Ltda., Santa fe de Bogota, 1994. pp. 226 - 240.
5. Situación actual de los programas preventivos de salud bucal en el contexto del Sistema General de Seguridad Social en Salud. URL disponible en: http://www.odontologos.com.co/articu.asp.

6. Cornejo A, Rojas C. Desarrollo de habilidades de aprendizaje en niños y niñas en riesgo de deserción escolar a través del estudio ejecución e interpretación musical. Unidad de investigación y desarrollo estratégico JUNAEB, 1994.

7. Carta de Ottawa para la promoción de la salud $17-21$ Nov 1986, Canadá.

8. Programa Latinoamericano para la Salud Bucal: Sonrie Latinoamérica. Revista FOLA ORAL 1999.

9. Louis K, Sánchez A, Vargas I, Villegas O. Promoción, Prevención y Educación para la Salud. Editorial Nacional de Salud y Seguridad Social: 2003.

10. Belloso N, Hernández NZ, Rivera L, Morón A. Efectividad de los programas de educación para la salud bucal en niños en edad escolar. Ensayo Experimental. Acta Científica Venezolana 1999; 50: 42 - 47.

11. American Dental Association, Bureau of Economic Research and Statistics. A motivational study of dental care. J Am Dent Assoc 1995; 56: 434 - 443, 566 - 574, 745 - 751, $911-917$.

12. Bay I. Undersogelse over plaqueforemkomsten og gingivas tilstand hos skoleborn y alderen 11-13 ar. Licentiatafhandling fra. Kobenharns. Tandlaegehojskoles. Afdeling for Paradontalogi. 1996.

13. García Godoy F. La salud como parte del proceso de socialización. Boletín Odontología Pediátrica 1996; 2.

14. Lindhe J, Koch $\mathrm{G}$. The effect of supervised oral hygiene on the gingiva of children. J Periodont Res 1995; 1: 260 $-267$.

15. Sheiham A, Plamping D. Bases científicas para la prevención y el tratamiento precoz de las enfermedades dentales más comunes. Vitoria: Servicio Central de Publicaciones, Gobierno Vasco, 1990: 61 - 65.

16. De la Cuesta C. Proinapsa-UIS. Investigación Cualitativa. Metodología de la Investigación. Diciembre 1998.

17. Secretaria de Salud-PROINPSA-UIS. Sana que Sana Despierta tus Ganas. Editorial Molino de Tinta 1999.

18. Hapkiewiez WG. Children's reactions to cartoon violence. J Clin Child Psychol 1979: 30 - 34.

19. Paavonen EJ, Pennonen M, Roine M, Valkonen S, Lahikainen AR. TV exposure associated with sleep disturbances in 5-to 6-year-old children. J Sleep Res 2006; 15: 154 - 161.

20. República de Colombia. Ministerio de Educación Nacional. Escuela y Desplazamiento. Una propuesta Pedagógica. Segunda Versión. Impresol Ediciones. URL disponible en: www.colombiaaprende.edu.co

21. Cabrera GA. Teorías y modelos en salud pública. Colombia Médica 2004; 35: 164 - 168.

22. Vilches L. La calidad de la ficción televisiva para niños. $1-28$ [fecha de acceso: febrero de 2006]. URL disponible en: http://www.audiovisualcat.net/publicacions/Q8calidad.pdf

23. Garcia A. Influencias, valores y concepciones en la creación de textos. URL disponible en: www.afsedf.sep. gov.mx 